\title{
The Formation of Elite Communication Networks in Malawi: A Bayesian Econometric Approach
}

\author{
Christian Aßmann, Eva Krampe, and Christian Henning
}

\section{Introduction}

Lobbying is commonly recognized as a public mechanism to induce policy makers to follow the interests of well-organized groups. Therefore, lobbying is criticized for distorting policies in favor of specific interests at the expense of society. Nevertheless, such political influence activities can also be understood as a mechanism by which interest groups signal their policy preferences. That is, lobbying conveys socially valuable information about the consequences of policies from society to political agents. If better-informed political agents now choose policies that increase social welfare, the provision of strategic information through lobbying can outweigh the negative distortionary effects (Ball 1995 and literature cited therein). Such arguments for the informational benefits of lobbying are also in line with the so-called wisdom of the crowd hypothesis. The wisdom of the crowd hypothesis suggests that a group of relatively uninformed individuals will collectively have much more knowledge than will any single member of the group (Galton 1907). Such a situation would enable political agents to choose better policies if they receive individual information via communication in elite networks.

\footnotetext{
C. Aßmann $(\bowtie)$

University of Bamberg, Chair of Statistics and Econometrics, Bamberg, Germany

e-mail: christian.assmann@uni-bamberg.de

E. Krampe

European Investment Bank, Luxembourg City, Luxembourg

C. Henning

Department of Agricultural Economics, Kiel University, Chair of Agricultural Policy, Kiel, Germany
} 
The major factor determining whether the informational benefits in fact outweigh the distortionary costs is the structure of the political elite's communication network. An important issue here is the tradeoff between the efficient policy learning of individual decisionmakers and a potential policy bias in the whole network that induces negative effects on overall economic performance. Political agents learn efficiently about the impacts of policy decisions on the economic system if they choose communication partners similar in political interests to themselves. Festinger (1954) argues that similar others offer relevant information and that similarity in interests is a well-known determinant of, for instance, friendship. In terms of policy learning, having communication ties with organizations that have similar interests to oneself reduces biased information signals and allows for an individually efficient communication process. However, such individually rational information-gathering routines also lead to policy distortions in favor of the group with the same interests as the political decisionmakers.

We suggest an empirical approach allowing for quantitative analysis of the informational value and the distorting nature of real-world knowledge diffusion within a country's political elite. ${ }^{1}$ Theoretical and observational studies suggest that political actors choose ties with others in a rational and predictable manner (Carpenter et al. 1998, 2004). In particular, the study tackles the following set of questions in order to provide valuable information for designing evidence-based policy formulation processes. Is the network-generating process individually or globally efficient, i.e., is it not distorted in favor of special interests with regard to policy learning? Do structural factors, similar political views, or the level of an alter's expertise determine the choice of contact? Do individual levels of political expertise lead to higher connectivity with other organizations?

We address these questions based on data collected via a series of face-to-face interviews with Malawi's political elite in 2010. This survey has already been described in detail in Chapter "A Network Based Approach to Evaluate Participatory Policy Processes: An Application to CAADP in Malawi” of this volume. The methodological challenge in assessing determinants of elite communication networks with survey data is dealing soundly with missing data. Despite the highest efforts in fieldwork, survey data is almost inevitably subject to item and unit non-response. Our estimation strategy addresses the mentioned data features by adapting the Bayesian estimation scheme for binary probit models based on the Markov Chain Monte Carlo (MCMC) methodology, namely Gibbs sampling, as suggested by Albert and Chib (1993). Based on a sample from the posterior distribution of the model parameters, obtained via iterative sequential sampling from the full conditional distributions, parameter estimates are given as sample moments. This estimation technique, using the device of data augmentation proposed by Tanner and Wong (1987), is well suited to deal with missing values in

\footnotetext{
${ }^{1}$ We focus on expert information networks because our main interest lies in understanding information-gathering routines of a country's elite. Studying determinants of political support networks and evaluating the nature of non-informative lobbying is left.
} 
explaining factors and missing values within the dependent network relationship. The vector of model parameters subject to posterior inference is augmented to also include the missing values of explaining variables and missing network relationships, where draws for the missing values within explaining factors are then obtained via sequential regression trees, providing non parametric approximations of the underlying full conditional distributions (Burgette and Reiter 2010). The proposed modeling thereby accounts for the uncertainty within parameter estimation due to missing values, as discussed in Butts (2003). We provide a model fitness criterion that allows for gauging the predictive capability of the suggested empirical framework and comparison of non-nested model specifications.

Empirical results suggest that common meeting opportunities and political influence are important determinants of the probability of observing a tie between a pair of organizations, while knowledge is an important but not leading determinant of communication. There is no evidence that information diffusion is affected by interest bias in Malawi. In terms of designing a political communication process, the results suggest that supporting umbrella organizations should increase information flow in the elite network.

This chapter proceeds as follows. We first describe determinants of political communication and corresponding empirical data. Next, we introduce the estimation strategy and the approach to model comparison. This is followed by study results and conclusions.

\section{Determinants of Political Communication Networks}

In this section, we first review determinants of elite communication structures as typically discussed in literature on political influence of interest groups and social network formation. Next, we provide a description of the variables used to assess empirically the determinants of communication.

\subsection{Theoretical Considerations}

Models used to describe the evolution of ties within networks commonly fall into two groups: preference-driven models and structure-driven models. To accommodate both approaches, we propose three main categories of determinants of political communication: (i) homophily in political interests, (ii) political knowledge or expertise, and (iii) structural factors (see Fig. 1). The first two categories rely upon the preference-driven approach to explain tie formation, while the third category summarizes the structural constraints organizations face in making contacts. 


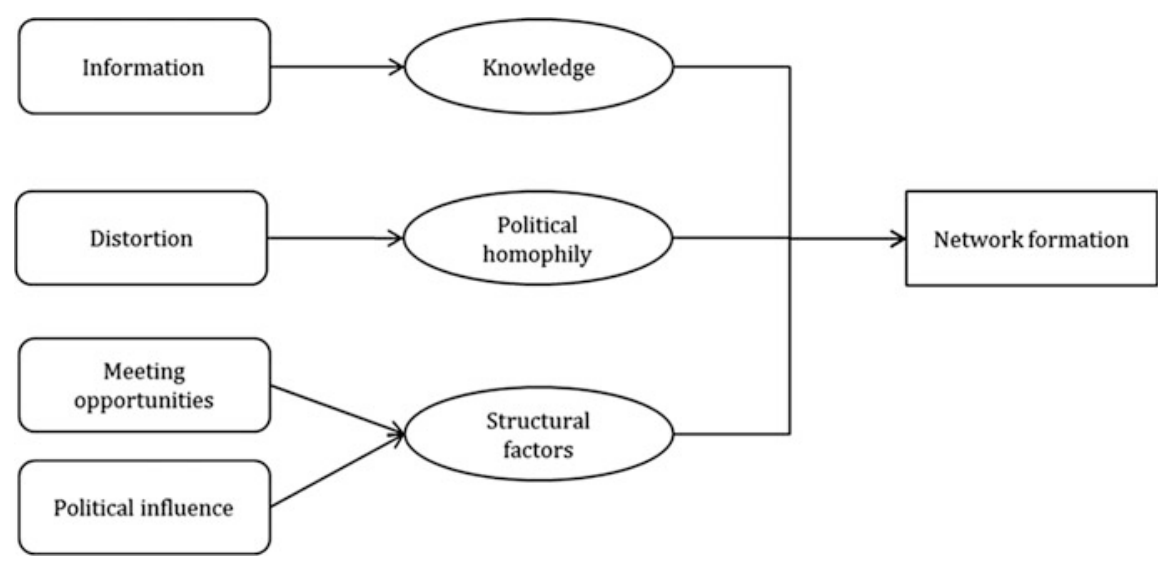

Fig. 1 Determinants of network evolution. Source: Authors

With regard to the first two categories, it is important to consider the two main roles of lobbying, i.e. informing and distorting. Several studies argue for the informational role of lobbying based on theoretical derivations from signaling games (Austen-Smith 1993; Ball 1995; Lohmann 1993). They emphasize that politicians are better able to choose efficient policies if they are being lobbied. Thus, it is rational for political agents to contact nongovernmental organizations with high expertise in a specific policy domain in order to reduce the uncertainty inherent in policy choices. For example, a political goal of agricultural policy is to achieve food security. Based on the dominance of knowledge in tie choice, policymakers should seek advice from organizations with high expert knowledge on, e.g., how a fertilizer subsidy affects food production, household income, and food prices, in order to launch goal-oriented policies.

With regard to expertise as a driver of nongovernmental-nongovernmental relations, consider that expert information is costly and not always publicly available. Nevertheless, an organization's influence on the beliefs of decisionmakers depends primarily on the organization's expertise. Therefore, an organization has the incentive to invest in contact making with experts to reduce uncertainty in their policy beliefs and to increase their reputation as well-informed communication partners.

However, getting informed comes with a price, according to lobbying theories. Information is seldom unbiased and mostly reflects an organization's position, which is biased according to political interests. This bias component leads to policy distortions at the expense of the public interest, if interests are not represented equally. Additionally, it determines a political actor's information-gathering routines. The latter results from the fact that receiving information from sources with similar interests to oneself lowers the likelihood of receiving information that does not match one's own interests in the state of the world (Festinger 1954; 
Austen-Smith 1993). ${ }^{2}$ Accordingly, communicating with organizations with similar political interests reduces the fiscal, emotional and processing costs of policy learning. It becomes rational for individuals to systematically choose alters that are similar in interests. Therefore, a commonly accepted determinant of tie choice, homophily, can also be applied to understand policy network evolution (for experimental evidence on political homophily as a driver of tie choice, see Knoke (1990), Pappi and Henning (1999), and Moody (2001). ${ }^{3}$ In summary, political homophily as a determinant of political communication lowers the likelihood of biased signals for the receiver of information but, assuming an unequal representation of interests and a negative correlation between knowledge and bias, increases the probability of biased, low-value information diffusion in the overall network.

Structural approaches argue that contact opportunities influence an actor's ties. Consider overlapping membership in organizations as well as formal and perceived political influence and human resources as structural determinants of communication choices. Theoretical arguments for overlapping membership in organizations as determinant are twofold. First, we lean on McPherson et al. (2001), who point out that meeting opportunity determines the formation of friendships in school. Transferring this idea to political communication, membership in umbrella organizations or common membership in organizations, as indicators for meeting opportunities, increases the probability that a pair of organizations forms a communication tie. At the same time, a common worldview might determine membership in an (umbrella) organization and thereby increase the trust an organization has in the information of other organizations with the same memberships. That is, an organization will seek information from another organization if a third party links them both (Holland and Leinhardt 1971). ${ }^{4}$

Another important determinant is an organization's power to influence legislation (Huckfeldt and Sprague 1995; Knoke et al. 1996). Given the purpose of lobbying as an interest-mediation mechanism, lobbying organizations contact highly influential actors within the political elite in order to ensure that their members benefit from final policy decisions. We therefore expect that the higher the perceived influence of an actor receiving information is in a specific policy domain, the more likely it is that organizations will contact this actor. We choose perceived influence and not formal political power for two main reasons. First, we argue in line with Shepsle and Weingast (1987) that formal institutional rules cannot explain observed power distributions. With regard to developing countries,

\footnotetext{
${ }^{2}$ Austen-Smith and Wright argue for the contrary effect of preference similarity in tie creation. Interest groups, i.e. organizations try to contact organizations with whom they disagree in order to convince them.

${ }^{3}$ On the concept of homophily in network evolution theories, see Lazer et al. (2008), McPherson et al. (2001) or Huckfeldt and Sprague (1995).

${ }^{4}$ The informational efficiency model contradicts the idea that a common link to a third party increases the likelihood of information exchange between a pair of organizations. On the contrary, this model states that organizations will drop ties to organizations with whom they are linked by a third party due to information redundancies (Carpenter et al. 2004).
} 
consider also the work of Bratton (2007), who argues that the rule of law is often weakly developed even if it is not completely absent in developing countries. Political power tends to be intensely concentrated around the president, and as a result his cabinet becomes more powerful in policymaking (van der Walle 2003). Further, considering only formal political power would dismiss the informal influence of international organizations in developing countries. Second, we argue that using perceived influence instead of formal power will not bias results. Formal political power usually is highly correlated with the perceived influence of actors endowed with formal power. Moreover, employing the concept of perceived influence has the advantage of reflecting both informal and formal political power distributions with one measure.

Finally, consider networking time as a scare resource of an organization, as hiring and paying staff is cost intensive and budgets are usually constrained. Given the time-consuming nature of forming and maintaining relationships, the number of staff, therefore, determines the contact opportunities that exist between a pair of organizations (Carpenter et al. 1998, 2004).

In summary, theoretical considerations offer two insights on the evaluation of participatory policy processes. First, as network formation can be preferencedriven, bias in favor of a specific group can occur and resulting policy decisions will be at the expense of the public. Nevertheless, expertise can be a major determinant of tie formation, as all actors seek to reduce uncertainty inherent to policy belief formation. Second, according to structuralist approaches, exogenous actors can influence the network structure by means of increasing meeting opportunities, e.g., joining umbrella organizations and increasing the number of staff.

\subsection{Empirical Determinants of Communication}

According to our theoretical considerations, our set of empirical variables is differentiated into three classes: (i) variables describing political homophily, (ii) variables indicating individual knowledge, and (iii) variables related to structural factors. For further information on the study that collected data for these variables, see Chapter "A Network Based Approach to Evaluate Participatory Policy Processes: An Application to CAADP in Malawi".

Political Homophily We approximate political homophily by a distance index of political interests (distance). Such an index provides dyad-specific information on the probability of observing communication between elite members due to similarity in policy interests. The index summarizes the distances in interest between two actors concerning the preferred dimension of the state of the world. We selected eight dimensions for representing the state of the world that actors address with designing agricultural policy programs (see Table 1). The index is calculated as a Euclidean distance function based on the policy interests of actor $\mathrm{i}$ and actor $\mathrm{j}$ in dimension $X^{(z)}$ with $\mathrm{z}=1, . ., 8$ : 
Table 1 Description of interests: state of the world

\begin{tabular}{|c|c|c|c|}
\hline Dimension & Common interests & Conflicting positions & $\varnothing$ interest \\
\hline $\begin{array}{l}\text { Welfare: } \\
\text { smallholders }\end{array}$ & $\begin{array}{l}\text { Reduce hunger and } \\
\text { malnutrition }\end{array}$ & Political market interventions & 21 \\
\hline Poverty reduction & Poverty reduction & $\begin{array}{l}\text { Achievable poverty level } \\
\text { (short-term) }\end{array}$ & 18 \\
\hline $\begin{array}{l}\text { Welfare: agr. } \\
\text { export sector }\end{array}$ & Foreign currency earnings & Political market intervention & 14 \\
\hline Budget & $\begin{array}{l}\text { Development of the } \\
\text { agricultural sector }\end{array}$ & $\begin{array}{l}\text { Share of agr. budget in total } \\
\text { budget }\end{array}$ & 13 \\
\hline $\begin{array}{l}\text { Environmental } \\
\text { sustainability }\end{array}$ & $\begin{array}{l}\text { Conservation of natural } \\
\text { resources }\end{array}$ & $\begin{array}{l}\text { Budget priority of environmen- } \\
\text { tal sustainability }\end{array}$ & 12 \\
\hline Gender issues & $\begin{array}{l}\text { Lessen the vulnerability } \\
\text { of the poor }\end{array}$ & $\begin{array}{l}\text { Gender specific policy } \\
\text { programs }\end{array}$ & 10 \\
\hline $\begin{array}{l}\text { Welfare: non-agr. } \\
\text { industry }\end{array}$ & Economic growth & Political market intervention & 6 \\
\hline $\begin{array}{l}\text { Welfare: urban } \\
\text { consumers }\end{array}$ & $\begin{array}{l}\text { Food provision to urban } \\
\text { population }\end{array}$ & Level of food prices & 5 \\
\hline
\end{tabular}

Source: The Ministry of Agriculture and Food Security, Republic of Malawi (2010), Government of Malawi (2006), own data

$$
\text { distance }_{i j}=\sum_{z=1}^{8}\left(X_{i}^{(z)}-X_{j}^{(z)}\right)^{2}
$$

Official policy documents provide the basis to extract the dimensions of the state of the world in a respective country. In the case of Malawi, consider the Malawi Growth and Development Strategy (MGDS) and the Agriculture Sector Wide Approach (ASWAp) as important policy programs (Government of Malawi 2006, The Ministry of Agriculture and Food Security, Republic of Malawi 2010). Table 1 describes which policy interests evolve in society that drive political behavior according to these two major policy documents. Interests are listed in descending order of average interest over interviewed organizations. Further, Table 1 lists common interests and conflicting positions that occur within one specific dimension of the state of the world. While common interests will drive political homophily and thereby communication, conflicting positions increase the potential for policy deadlocks but allow also for policy learning. Consider, for example, the welfare of smallholders. Actors might be equally interested in reducing hunger and malnutrition but have different experiences and information about the political strategy to reach their common aim. One actor might favor input subsidies to increase maize yields, the other one might consider budget spending on extension services as a more efficient policy strategy. Information exchange between these two actors can help to choose a strategy that best fits their common interests.

Knowledge Our strategy to identify an organization's level of knowledge is twofold. First, as knowledge is hardly observable, we use the age of the organization 
(age) and the organization's degree of specialization in agriculture (specialization) to approximate political knowledge. In our study, age equals 2000 minus year of foundation, and specialization relates to an organization's effort spent on agricultural issues.

Second, we use an alternative indicator that directly measures the technological knowledge of actors regarding the transformation of CAADP policies into policy outcomes based on a computable general equilibrium (CGE) model. In particular, Henning (2012) models the impact of different CAADP policies on the eight relevant policy concerns within an extended CGE approach calibrated for Malawi. As described in detail in Chapter "Whither participation? Evaluating participatory policy processes with the CGPE approach: The case of CAADP in Malawi" of this volume, based on this CGE approach, the optimal CAADP policy positions from the viewpoint of different governmental and nongovernmental organizations can be identified - where optimality involves maximizing the organizations' political support functions-while modeling the technical translation of CAADP policies into policy concerns evolves according to the extended CGE. Comparing the theoretically derived optimal policy positions with the policy positions stated by organizations during our interview implies a measure of an organizations' political knowledge. In particular, Henning (2012) calculates the Euclidean difference between the theoretically implied and empirically stated policy position (see Chapter "A Network Based Approach to Evaluate Participatory Policy Processes: An Application to CAADP in Malawi"). We use this measure as a direct indicator of the political knowledge of an organization (expertise) in our econometric analysis. As documented in detail in Chapter "A Network Based Approach to Evaluate Participatory Policy Processes: An Application to CAADP in Malawi", on average, farm and civil society organizations have the highest political knowledge, while politicians and, in particular, political parties have the lowest political knowledge. Donor organizations take a middle ground in political knowledge.

Structural Factors Because the perception of an organization as influential in policymaking will influence its probability of forming ties, we use a reputation network for identifying an organization's political reputation (reputation). This variable will further serve as a proxy of an organization's legislative power. Please note that reputation is highly correlated with the lobbying power calculated in Chapter "A Network Based Approach to Evaluate Participatory Policy Processes: An Application to CAADP in Malawi" based on simulated support network data. To account for the meeting opportunities between two organizations, we include the number of staff working on agricultural policy issues (staff) in our analysis. Information about organizational membership allows us to calculate a dyad-specific count variable that indicates how often two organizations were members of the same umbrella organization (same). Examples of umbrella organizations in Malawi are the Malawi Economic Justice Network (MEJN) and the Civil Society Agriculture Network (CISANET).We include the determinants as dyad-specific characteristics into our econometric model, i.e., sender- and receiver-specific individual 
variables are transformed into pair-wise distances. In addition, the individual determinants enter the model as sender- and receiver-specific variables.

Since homophily is a key term of interest in this analysis, we calculate Euclidean distance measures between sender- and receiver-specific values of specialization, age, staff, reputation and policy concerns (distance). The larger the values of these distance measures, the more organizations differ in terms of the respective issue. A negative value of the parameter estimate indicates that the probability of forming a tie increases with homophily in the respective dimension. A positive value suggests that heterophily has positive impacts on the probability of communication.

\section{Study Design and Econometric Model Framework}

\subsection{Study Design}

Identified relevant governmental and nongovernmental organizations are reported in Table A1 in the appendix. While Chapter "A Network Based Approach to Evaluate Participatory Policy Processes: An Application to CAADP in Malawi" describes the study design in detail and presents the data collected from parts (a), policy network data, and (b), policy preferences of the policy network survey conducted in Malawi, data collected from part (c) of the questionnaire is described below.

First, however, we explain the measurement of political homophily (distance) in more detail, as this variable is important within the analysis of network formation. Given our theoretical framework, political homophily relates to an organization's interests in specific policy concerns. Hence, in this study we use the interview data from the questions about interest, $X_{i}^{(z)}$ in the eight policy concerns, i.e. $\mathrm{z}=1, \ldots, 8$. Interests are ascertained by distributing 100 points across the eight dimensions of the state of world (identified in Table 1). For information on the data used to calculate expertise, please see Chapters "Modeling and Evaluation of Political Processes: A New Quantitative Approach" and "A Network Based Approach to Evaluate Participatory Policy Processes: An Application to CAADP in Malawi".

Part (c) of the survey asks questions about organizational attributes that inform about an organization's degree of specialization in agriculture (specialization), the year of foundation (to calculate age), and the number of staff engaged in agricultural issues (staff). Further, we asked organizations to name all umbrella organizations of which they are a member. With this information in hand, we calculate the dyad-specific count variable same, which informs about overlapping memberships in umbrella organizations between a pair of organizations. The mean of this variable reveals that, on average, two organizations in Malawi are jointly members of 1.3 organizations.

Summary statistics for all exogenous variables under consideration are given in Table 2. 
Table 2 Summary statistics

\begin{tabular}{l|c|c}
\hline Variable & Mean & SD \\
\hline Specialization & 0.652 & 0.305 \\
\hline Age & 26.027 & 20.288 \\
\hline Staff & 19.625 & 34.753 \\
\hline Reputation & 0.573 & 0.179 \\
\hline Same & 1.267 & 0.708 \\
\hline Distance & 0.314 & 0.146 \\
\hline Expertise & 0.641 & 0.177 \\
\hline
\end{tabular}

Source: Calculated by authors from own data

\subsection{Econometric Model}

We design an empirical model capturing key elements of the communication process between local elite members related to individual characteristics influencing the formation probability of a network tie. Individual characteristics are considered as important network determinants in terms of the prevailing homophily of network agents. For analyzing the process which establishes communication ties $\delta_{j i}$ or $\delta_{i j}$ between local elite members $i=1, \ldots, n$ and $j=1, \ldots, n$ with $i \neq j$ for the considered directed dichotomous network relationships, determinants of communication relationships are assessed within a probit framework, i.e. $\delta_{i j}=1$, if $\delta_{i j}^{*}>0$ and $\delta_{i j}=0$ else. Following Hoff and Ward (2004), the latent variable $\delta_{i j}^{*}$ relating determinants of communication with the observed network tie $\delta_{i j}$ is thereby parameterized as

$$
\delta_{i j}^{*}=W_{i j} \beta+W_{i} \kappa_{s}+W_{i} \kappa_{r}+h_{i j}+e_{i j}=Q_{i j} \theta+e_{i j},
$$

where $W_{i j}$ is a set of dyad specific variables, $W_{i}$ denotes a set of sender specific characteristics for individual $i, W_{j}$ is a set of receiver specific characteristics for individual $j . h_{i j}$ is assumed to capture distance effects and thus homophily and is hence parameterized in such a way to allow the aggregation of individual specific characteristics to the dyadic level, i.e.

$$
h_{i j}=\left|W_{i}-W_{j}\right| \gamma,
$$

and $\theta=\left\{\beta, \kappa_{s}, \kappa_{r}, \gamma\right\}$ summarizes all model parameters. Using a probit link, which corresponds to the assumption of a standard normal distribution for the latent error, i.e. $e_{i j} \sim N(0,1)$, allows for establishing a Bayesian estimation routine facilitated by Markov Chain Monte Carlo (MCMC) techniques. Parameter inference within a Bayesian setup is performed based on the posterior distribution defined via

$$
p(\theta \mid \text { data }) \propto L(\text { data } \mid \theta) \pi(\theta),
$$


where $L($ datal $\theta)$ denotes the model likelihood and $\pi(\theta)$ the assumed prior distribution of model parameters. Parameter inference is based on moments and quantiles of the posterior distribution. These are obtained on the basis of sample trajectories drawn from the posterior distribution. Sampling of parameters from their joint posterior distribution is achieved via iterative sampling from the full conditional distributions. The model likelihood is then given as

$$
L(\text { data } \mid \theta)=\prod_{i \neq j} \Phi\left(\left(2 \delta_{i j}-1\right)\left(Q_{i j} \theta\right)\right),
$$

where $\Phi(\cdot)$ denotes the cumulative standard normal distribution function. Given the above model structure, we adapt conjugate priors for all model parameters, i.e. a multivariate normal prior for parameter vector $\theta$ with the corresponding mean set to zero and diagonal covariance with variance set to 100 for each element. More details on Bayesian estimation via Gibbs sampling for this kind of models are given in Aßmann and Boysen-Hogrefe (2011). Next to parameter estimates, interpretation of results is provided by calculation of marginal effects, where the corresponding uncertainty is directly accessibly by means of the Gibbs output, see Aßmann and Boysen-Hogrefe (2011) for a more general discussion.

In addition, the use of Bayesian estimation allows for a conceptually straightforward treatment of missing values within both, the observed network relationship and the explaining variables. As empirical network data is most often based on personal interviews and survey data, missing values occur despite tremendous effort in fieldwork and questionnaire design. Missing values are especially troublesome, as a single missing value for a considered explaining characteristic for individual $i$ causes the potential loss of $n-1$ observed network relationships for assessing the link between the formation probability of a network tie and the considered individual characteristics as determinants thereof. Additionally, the parameter estimates would no longer reflect information on all network constituents. Thus proper estimation routines facilitating the use of variables with single missing observations are needed to perform proper statistical analysis incorporating the uncertainty in parameter estimation stemming from missing values. Dealing with missing values is performed using the MCMC device of data augmentation as suggested by Tanner and Wong (1987). The parameter vector $\theta$ is augmented to include the missing values in the explaining factors. Sampling from the full conditional distributions for these missing values is then incorporated within the iterative sampling scheme providing draws from the posteriori distribution $p(\theta)$ data). For the considered probit model allowing for analysis of a directed dependent network relationship, the sampling proceeds by iterating the following basic steps, see Albert and Chib (1993).

1. Sampling of the latent variable $\delta_{i j}{ }^{*}$ from truncated normal distributions with means given by the linear regression setup and variance of one. The truncation at zero from above is $\delta_{i j}=0$ and from below if $\delta_{i j}=1$, see Aßmann and Boysen- 
Hogrefe (2011) for details on the corresponding moments of this full conditional distribution.

2. Sampling of the parameters $\beta, \kappa_{s}, \kappa_{r}$ and $\gamma$ from full conditional distributions underlying the linear regression setup for latent variable $\delta_{i j}{ }^{*}$, see Aßmann and Boysen-Hogrefe (2011) for details on the corresponding moments of this full conditional distribution.

3. Sampling from the full conditional distributions of missing values.

a. In case of missing values in one of the explaining variables, these are obtained using non-parametric approximations for the full conditional distributions as suggested by Burgette and Reiter (2010). Note that for this class of empirical network models, where the set of individual characteristics is assumed to explain the formation probability of a network tie, only few observations are at hand to provide a realistic approximation of the full conditional distribution. If the number of observations required by the non-parametric approach of Burgette and Reiter (2010) is not reached, draws for the missing values are obtained from the observed unconditional distribution as the only approximation of the full conditional distribution at hand to obtain draws for this variables.

b. In case of missing values in the dependent variable, sampling from a binary distribution with success probability $\phi\left(Q_{i j} \theta\right)$ yields a draw from the full conditional distribution.

Successive sampling from the outlined full conditional distributions establishes a sample from the posterior distribution facilitating inference with regard to parameters based on the empirical moments. Although parameter estimates allow for direct assessment of the direction in which explaining factors influence the formation probability of a communication tie, marginal effects provide a quantification of the effect of a change in determining factors on the probability of a communication relation. Marginal effects are conceptually given as $\frac{\partial \operatorname{Pr}\left(\delta_{i j}=1 \tilde{Q}\right)}{\partial \tilde{Q}}$, where $\tilde{Q}$ denotes a particular state of the considered control variables, e.g., the mode. An estimate of the marginal effects is readily obtained from the output of the Gibbs sampling scheme as

$$
\frac{1}{S} \sum_{i=1}^{n} \phi\left(\tilde{Q} \theta^{(s)}\right) \theta^{(s)}
$$

where $\phi(\cdot)$ denotes the standard normal density and $\theta^{(s)}, s=1, \ldots, S$, denote the sampled trajectories of all considered model parameters. In general estimates will be based on 10000 draws, i.e., $S=10000$, where discarding the initial 2000 draws have been found sufficient to mitigate the effect of burn-in.

However, whilst the necessity to deal with missing values within the explaining factors is inherent given the considered empirical network model for the surveyed network data, it is nevertheless important to check carefully the adequacy of the considered empirical model. While valid point and interval estimates are readily 
available for the above suggested approach for dealing with missing values, other standard measures for gauging model fitness, like e.g. $F-t e s t s$, are not readily available. Note that this applies also to alternative approaches allowing for handling of missing data, see Raghunathan et al. (2001). As a natural approach to gauge model fitness is based on the capability of the empirical network model to provide accurate forecasts, the following outlines one possibility to calculate an overall measure of model fitness. The situation of a network observed with missing values poses a methodological challenge, as the benchmark for assessing the prediction accuracy, i.e. the true relationship between network members, remains unobservable. As a formal prediction criteria, we use the area under the curve (AUC) measure derived from the receiver operator characteristics (ROC) curve approach proposed by Egan (1975). In order to function as a valid criterion of model fitness, the AUC measure has to be combined with a pseudo out-of-sample experiment gauging against possible overparameterization, see Aßmann and Boysen-Hogrefe (2011) for a review of this approach in cross validation experiments for binary panel data. One possibility to design the out-of-sample is to split the network constituents into four quarters forming a partition of the set of network constituents, where other splits are also possible. Parameter estimation is based on the network formed by three quarters of the network constituents, where parameter estimates are then used to predict the network formed by the left quarter of network constituents. Adapting a fourfold split yields a total of four possible combinations. Since in our situation the underlying network involves missing data, the predicted network resulting from complete sample estimation serves as a prediction reference. Note that this approach allows for a comparison of even non-nested model specifications.

\section{Empirical Results}

Estimation results concerning the explanatory factors suggested by theory are provided in Table 3 below. Although parameter estimates show the direction in which explanatory factors influence the probability of tie formation between two organizations, regression coefficients (columns 3 and 4) provide no correct quantitative description of the relationship between the probability of communication ties and changes within the explanatory factors. The relative importance of the different explanatory factors can be gauged based on marginal effects (columns 6 and 7). The in-sample AUC measure reveals that our approach to dealing with missing values and the suggested model specification result in high prediction accuracy of communication ties between organizations. Using the random graph model as an illustrative benchmark (corresponding AUC measure of 0.5), the out-of sample AUC measures point to the significantly increased prediction accuracy due to the considered set of explaining factors. 
Table 3 Estimation results (dependent variable is: if $\mathrm{A} \rightarrow \mathrm{B}$, tie $=1$; 0 otherwise)

\begin{tabular}{|c|c|c|c|c|c|c|}
\hline & \multicolumn{4}{|c|}{ Parameter estimates } & \multicolumn{2}{|c|}{ Marginal effects } \\
\hline & Mean & SD & $2.50 \%$ & $97.50 \%$ & Mean & SD \\
\hline Constant & -1.254 & 0.468 & -2.185 & -0.341 & - & - \\
\hline \multicolumn{7}{|l|}{ Homophily } \\
\hline Specialization & -0.672 & 0.201 & -1.068 & -0.281 & -0.223 & 0.065 \\
\hline Age & 0.001 & 0.004 & -0.007 & 0.009 & 0.000 & 0.001 \\
\hline Expertise & 0.423 & 0.372 & -0.315 & 1.147 & 0.144 & 0.128 \\
\hline Staff & -0.01 & 0.003 & -0.016 & -0.004 & -0.003 & 0.001 \\
\hline Reputation & -0.949 & 0.346 & -1.619 & -0.266 & -0.316 & 0.116 \\
\hline Distance & 0.41 & 0.366 & -0.295 & 1.141 & 0.142 & 0.129 \\
\hline \multicolumn{7}{|l|}{ Structural } \\
\hline Same & 0.814 & 0.116 & 0.585 & 1.043 & 0.274 & 0.054 \\
\hline \multicolumn{7}{|l|}{ Sender-specific } \\
\hline Specialization & -0.3 & 0.246 & -0.776 & 0.189 & -0.105 & 0.087 \\
\hline Age & 0.006 & 0.004 & -0.002 & 0.013 & 0.002 & 0.001 \\
\hline Expertise & -1.593 & 0.392 & -2.329 & -0.786 & -0.53 & 0.128 \\
\hline Staff & 0.02 & 0.003 & 0.014 & 0.026 & 0.007 & 0.001 \\
\hline Reputation & 0.241 & 0.336 & -0.413 & 0.896 & 0.078 & 0.111 \\
\hline \multicolumn{7}{|l|}{ Receiver-specific } \\
\hline Specialization & 0.339 & 0.17 & 0.005 & 0.662 & 0.111 & 0.054 \\
\hline Age & -0.007 & 0.003 & -0.014 & -0.001 & -0.002 & 0.001 \\
\hline Expertise & 0.062 & 0.293 & -0.517 & 0.642 & 0.023 & 0.099 \\
\hline Staff & 0.02 & 0.003 & 0.014 & 0.026 & 0.007 & 0.001 \\
\hline Reputation & 4.591 & 0.325 & 3.93 & 5.23 & 1.539 & 0.191 \\
\hline Predicted (rows)/Observed (columns) & \multicolumn{3}{|l|}{0} & \multicolumn{3}{|l|}{1} \\
\hline 0 & \multicolumn{3}{|l|}{240} & \multicolumn{3}{|l|}{43} \\
\hline 1 & \multicolumn{3}{|l|}{429} & \multicolumn{3}{|l|}{620} \\
\hline AUC (in-sample/out-of-sample) & \multicolumn{6}{|c|}{$0.7262 / 0.6724$} \\
\hline
\end{tabular}

Source: Calculated by authors from own data

\subsection{Homophily in Interests and Other Determinants}

In Table 3, estimated parameters and marginal effects show that homophily in an organization's attributes increases the probability that it will interact. All significant variables have a negative sign. If organizations are similar in terms of specialization, staff, and reputation, the probability of forming a tie increases. Inspection of the marginal effects reveals no high quantitative effect of an increase in the difference of staff between two organizations on the probability of forming a communication tie, while increasing homophily in reputation and specialization has a high quantitative impact. These findings point at the need to look not only at parameter estimates but also at marginal effects to assess the quantitative effects correctly. We find no significance for homophily in age or expertise. 
Political homophily (distance) is not an important determinant of communication. With regard to the distortionary effects of political homophily, this finding suggests less biased policy decisions. Nevertheless, organizations need to adopt efficient information-processing routines to filter received information in terms of a sender's special-interest bias.

\subsection{Knowledge}

Next, we take a closer look at knowledge as a determinant of tie formation. We start with the proxy for an organization's level of knowledge: specialization. A receiver's probability of gaining information by communication increases with its level of specialization. A sender's level of specialization is not significantly associated with tie formation. The negative and significant sign of the difference in specialization implies that communication partners are likely to be similar in their level of specialization and thereby in their level of knowledge. With regard to expertise transmission in the network, this result points at isolated clusters of knowledge that prohibit the spread of knowledge, where receivers are already well informed about policy impacts.

Age as another proxy reveals that the younger an organization, the higher the probability of receiving information from others. If we now put great age on a high level with knowledge, the process enables transmission of knowledge from the long-established, more experienced organizations to the younger and less experienced ones. Please note that similarity in age does not significantly prohibit tie formation.

As these variables are at best proxies for knowledge, we consider a further advanced indicator expertise, which is derived from our own survey data and Malawi's CGE. Note that low values of expertise indicate a high level of knowledge about impacts of policy decisions on the state of the world. A sender's high value for expertise is especially associated with a greater probability of communication. Since homophily in expertise has no significant impact on the probability of forming a communication tie, knowledge will not circulate within a cluster of highly informed organizations. Consequently, less-informed organizations are able to receive information from experts ceteris paribus, and well-informed policy decisions are likely to happen.

We summarize for knowledge as a determinant of communication that young organizations receive information from older ones and that knowledge is spread among organizations with divergent levels of knowledge. In fact, the marginal effect of sender-specific expertise states that knowledge highly influences the probability of senders to form ties. However, if specialization in agriculture is well correlated with knowledge, homophily in specialization would prohibit knowledge transmission. In our case, we observe the contrary. Specialization is not highly 
correlated with expertise (correlation equals 0.069). Hence, we suggest discussing the variable specialization more generally in terms of an organization's main activity field. That is, organizations with heterogeneous activity fields but high capacity can still be well-informed organizations. Good cases in point are donor organizations. It is well recognized that donors rarely specialize in a sector but handle several problem areas in a developing country. With this example in mind, the negative impact of homophily in specialization does not trigger information transmission but simply reveals that organizations with similar activity fields will form ties more often ceteris paribus.

\subsection{Structural Factors}

Turning now to structural factors as determinants of communication, we observe several significant variables. One factor that determines an organization's probability of participating in elite communication is the number of staff (staff). This finding is in line with other studies, see for instance Carpenter et al. (2004). For senders and receivers an increase in the number of staff increases their probability of communicating with others. We again observe homophily among organizations. That is, organizations of about the same size are more likely to communicate with each other. However, inspection of the marginal effects reveals no high quantitative effect of an increase in the number of staff or in the difference of staff between a pair of organizations on the probability of communicating.

A receiver's perceived influence (reputation) appears to increase the probability that actors will contact highly influential others. Consider here that reputation is highly correlated with formal and informal political power. The result is intuitive, since it suggests that senders try to increase the probability that legislation will favor their interests by providing expert information to highly influential organizations. The observed marginal effect of receiver-specific reputation reveals a great influence of this determinant on network evolution. The negative sign on the difference in reputation suggests that organizations similar in reputation form communication clusters. Consequently, less influential organizations are less likely to form ties to powerful actors.

Another determinant of communication is overlapping membership in umbrella organizations between a pair of organizations (same). The more umbrella organizations are connecting $\mathrm{A}$ to $\mathrm{B}$, the more likely organization $\mathrm{A}$ is to communicate with organization $B$. Inspection of marginal effects reveals a high quantitative impact of overlapping membership in umbrella organizations on the probability of communicating. This finding is in line with the theoretical considerations. Common membership in umbrella organizations increases the trust between organizations and thereby increases the probability that the two exchange information. 
Further, common membership is a proxy for the opportunity structure to meet and communicate. 5

\section{Discussion}

Based on the empirical assessment, we conclude that overlapping membership in organizations and political influence are more important determinants of elite communication ties than knowledge in Malawi. We do not infer that knowledge can be neglected as a determinant or that an elite network does not spread information among actors. However, the high marginal effects of same and homophily in reputation narrow the impact of knowledge on tie formation, even if expertise significantly influences the probability of sending information. For illustration, the following calculations are performed to describe how overlapping membership in organizations (same) and their level of knowledge (expertise) influence the probability of forming a tie for senders. In fact, we calculate the effect of a change in same (expertise) from the minimum value to the maximal value observed in our sample. Therefore, probabilities to communicate are computed for each of the two determinants at these extreme positions averaging over all other determinants observed within the sample. The minimum of same corresponds to no overlapping organizations, the maximum to four overlapping organizations. The minimum level of knowledge is given by a value of 1.098 for expertise in our sample, while a value of 0.445 for expertise denotes the highest level of knowledge among the actors. ${ }^{6}$ An inspection of effects, see Table 4, reveals that increasing overlapping membership in organizations increases the probability of observing a tie between a pair of organizations by $29 \%$. However, if an uninformed sender gains as much knowledge as the best-informed actor in the sample, the probability of forming ties, with all other determinants fixed at their means except homophily in expertise, increases by 22 percentage points. Hence, joining other organizations would be ceteris paribus a better means than accumulating knowledge to increase the probability of sending information.

In terms of the bias/information tradeoff of participatory policy processes, results show that political homophily is not a significant determinant of communication. Therefore, at least regarding fundamental policy concerns, participatory policy processes allow for unbiased information diffusion in Malawi. However, two qualifications of this result are necessary. First, although political homophily does

\footnotetext{
${ }^{5}$ Please note that literature suggests that homophily in attributes might affect the opportunity structure to meet (see Lazer et al. 2008). We leave it to future work to disentangle the effect of meeting opportunity and homophily in interests and remind the reader to interpret the results carefully. Nevertheless, we think that our detailed measure of political homophily is neither correlated with overlapping membership in organizations nor affected by the same factors as the latter. Therefore, our estimations are not plagued by endogeneity or multicollinearity.

${ }^{6}$ Please note that we measure political knowledge via the Euclidian distance between stated and optimal policy position of an organization, i.e. the higher the distance the lower the knowledge.
} 
Table 4 Simulation of marginal effects: same and expertise

\begin{tabular}{l|l|l|l}
\hline \multicolumn{3}{l|}{ Same } & \multicolumn{2}{l}{ Expertise } \\
\hline Min/max & $\operatorname{Pr}\left(\delta_{i j}=1\right)$ & $\operatorname{Min} / \max$ & $\operatorname{Pr}\left(\delta_{i j}=1\right)$ \\
\hline 0 & 0.700 & 1.098 & 0.571 \\
\hline 4 & 0.997 & 0.445 & 0.790 \\
\hline
\end{tabular}

Source: Calculated by authors

Notes: All other variables, except the distance in expertise for the effect of expertise, are fixed at their means

not play a role, homophily in general is still an important structural determinant of the network-generating process of political communication among Malawi's political elite. In particular, homophily in reputation as well as in specialization clearly discriminates communication between types of organizations. For example, our estimation results imply that, based on reputational homophily, international donor organizations have a significant higher probability of sending information to central ministries, i.e., the Ministry of Finance (MoF) and the Ministry of Agriculture and Food Security (MoAFS), when compared to an average national civil society organization. Second, despite homogeneous interests in fundamental policy concerns, heterogeneity of preferred policy positions among organizations can still result due to biased political beliefs. Hence, to limit policy biases due to wrong beliefs it is important that communication ties are determined by the political knowledge of the sender. Here, the strong marginal effect for sender-specific political knowledge certainly works in favor of unbiased political beliefs, but overall this effect is alleviated by structural factors as well as homophily effects determining the network-generating process. Thus, overall, only suboptimal political communication structures result.

\section{Conclusion}

This study analyzes the communication patterns among governmental, local stakeholder and international organizations in Malawi. We present an approach that is novel within network estimation as well as within political science. In terms of econometric analysis of surveyed network data, our approach is based on an extended binary regression framework. In fact, the model relies on a Bayesian estimation framework to handle missing data due to survey non-response. For political consultants, the framework enables learning about political communication processes in a country. Findings will enable them to design communication processes that increase the probability of well-informed, unbiased policy choices.

In addition to this, we explicitly analyze the information/distortion potential of participatory policy processes by employing two variables. First, we use an external measure of an actor's knowledge about policy impacts derived from a CGE model and survey data of the actor's policy preferences in order to analyze the impact of the actor's knowledge on its probability of communicating with others. Second, we employ an index of homophily in policy interests between a pair of organizations to 
describe the distortion potential. Insights about this tradeoff are valuable in order to evaluate the potential of participatory policy processes to increase the likelihood of improving total welfare delivering undistorted policies.

Empirical findings are presented for a case study in Malawi. Data was gathered in face-to-face interviews with local stakeholders, international organizations, and politicians in 2010. We find strong support for explanatory factors suggested by the two strands of literature about determinants of communication-the preferencedriven and structure-driven models. Overall, the most influential determinants of communication processes are an actor's reputation, overlapping membership in organizations and knowledge about policy impacts.

In terms of well-informed policy decisions, it is highly appreciated that knowledge about policy impacts increases a sender's probability of forming communication ties. Nevertheless, this positive result for the potential of participatory policy processes to increase well-informed policy choices is narrowed by the high influence of homophily in reputation on the probability of forming ties. Homophily in reputation will disable well-informed but less influential players to convey valuable information into the policy process. Further, joining other organizations increases the probability of communicating with elite members more than accumulating knowledge ceteris paribus. That is, promoting membership in umbrella organizations is a means to increasing information flow between groups. As overlapping membership in organizations relates to sharing common communication platforms, the CAADP approach of creating working groups on priority issues to work on policy proposals for pro-poor growth policy programs is an adequate intervention in the communication process to increase communication opportunities among organizations. However, at time of the interview round, an effective institutional organization of dialogue among stakeholders and between government and stakeholders was still not implemented.

The empirical analysis also shows that the probability of forming ties does not increase with homophily in relative interests in fundamental policy goals, e.g., poverty reduction via economic growth. Hence, although the identified networkgenerating process clearly discriminates between types of nongovernmental organizations, it still follows that policy decisions will not be fundamentally biased in favor of special interests. Nevertheless, policy bias might result since organizations have different levels of political knowledge, which is not fully reflected in the probability of sending information to powerful politicians. The latter results especially from the fact that, beyond knowledge, structural factors such as meeting opportunities, as well as reputational homophily, determine communication ties among organizations.

Moreover, even communication ties perfectly determined by political knowledge can still result in biased policies if average level of knowledge is rather low, i.e., political beliefs for all organizations are systematically biased. This point will be further elaborated in Chapter "Whither participation? Evaluating participatory policy processes with the CGPE approach: The case of CAADP in Malawi" below.

Finally, the perceived influence of organizations affects tie evolution in the elite network. Organizations are more likely to be contacted if they are highly influential. This finding is intuitive since organizations want to ensure that final policy 
decisions consider their knowledge about policy impacts, so that their members benefit from implemented policies.

\section{References}

Albert, J.A., and S. Chib. 1993. Bayesian Analysis of Binary and Polychotomous Response Data. Journal of the American Statistical Association 88 (422): 669-679.

Aßmann, C., and J. Boysen-Hogrefe. 2011. A Bayesian Approach to Model-Based Clustering for Binary Panel Probit Models. Computational Statistics and Data Analysis 55: 261-279.

Austen-Smith, D. 1993. Information and Influence: Lobbying for Agendas and Votes. American Journal of Political Science 3 (3): 799-833.

Ball, R. 1995. Interest Groups, Influence and Welfare. Economics and Politics 7 (2): 119-146.

Bratton, M. 2007. Formal versus Informal Institutions in Africa. Journal of Democracy 18: 96-110.

Burgette, L.F., and J.P. Reiter. 2010. Multiple Imputation for Missing Data via Sequential Regression Trees. American Journal of Epidemiology 172 (9): 1070-1076.

Butts, C.T. 2003. Network Inference, Error, and Informant (In)accuracy: A Bayesian Approach. Social Networks 25 (2): 103-140.

Carpenter, D.P., K.M. Esterling, and D.M.J. Lazer. 1998. The Strength of Weak Ties in Lobbying Networks: Evidence from Health-Care Politics in the United States. Journal of Theoretical Politics 10 (4): 417-444.

- 2004. Friends, Brokers, and Transitivity: Who Informs Whom in Washington Politics? Journal of Politics 66: 224-246.

Egan, J. 1975. Signal Detection Theory and ROC analysis, Series in Cognition and Perception. New York: Academic Press.

Festinger, L. 1954. A Theory of Social Comparison Processes. Human Relations 7 (2): 117-140.

Galton, F. 1907. Vox Populi. Nature 75: 450-451.

Government of Malawi. 2006. Malawi Growth and Development Strategy-From Poverty to Prosperity, Technical Report. IMF Country Report No. 07/55.

Henning, C.H.C.A. 2012. An Evolutionary CGPE-Approach to Assess Governmental Performance Gaps: Theory and Empirical Application to Agricultural Policy in Malawi. Working Paper presented at the Brown-bag Seminar. Washington, DC: IFPRI.

Hoff, P.D., and M.D. Ward. 2004. Modeling Dependencies in International Relations Networks. Political Analysis 12 (2): 160-175.

Holland, P.W., and S. Leinhardt. 1971. Transitivity in Structural Models of Small Groups. Small Group Research 2 (2): 107-124.

Huckfeldt, R., and J. Sprague. 1995. Citizens, Politics, and Social Communication. New York: Cambridge University Press.

Knoke, D. 1990. Political Networks: The Structural Perspective. New York: Cambridge University Press.

Knoke, D., F.U. Pappi, J. Broadbent, and Y. Tsujinaka. 1996. Comparing Policy Networks. Labor Politics in the U.S., Germany, and Japan. New York: Cambridge University Press.

Lazer, D., B. Rubineau, N. Katz, C. Chetkovich, and M.A. Neblo. 2008. Networks and Political Attitudes: Structure, Influence, and Co-evolution. HKS Faculty Research Working Paper Series RWP08-044, September 2008.

Lohmann, S. 1993. A Signaling Model of Informative and Manipulative Political Action. American Political Science Review 87 (2): 319-333.

McPherson, M., L. Smith-Lovin, and J.M. Cook. 2001. Birds of a Feather: Homophily in Social Networks. Annual Review of Sociology 27: 415-444.

Moody, J. 2001. Race, School Integration, and Friendship Segregation in America. American Journal of Sociology 70 (3): 679-716. 
Pappi, F.U., and C.H.C.A. Henning. 1999. The Organization of Influence on EC's Common Agricultural Policy: A Network Approach. European Journal of Political Research 36 (2): 257-281.

Raghunathan, T.E., J.M. Lepkowski, J. van Hoewyk, and P. Solenberger. 2001. A Multivariate Technique for Multiply Imputing Missing Values Using a Sequence of Regression Models. Survey Methodology 27 (2): 85-95.

Shepsle, K.A., and B.R. Weingast. 1987. The Institutional Foundations of Committee Power. American Political Science Review 81 (1): 85-104.

Tanner, M., and W. Wong. 1987. The Calculation of Posterior Distributions by Data Augmentation. Journal of the American Statistical Association 92 (398): 528-540.

The Ministry of Agriculture and Food Security, Republic of Malawi. 2010. Agriculture Sector Wide Approach (ASWAp). Malawi's Prioritised and Harmonised Agricultural Development Agenda. http://www.caadp.net/pdf/Investment\%20plan\%20-\%20Malawi.pdf

Van der Walle, N. 2003. Presidentialism and Clientelism in Africa's Emerging Party Systems. Journal of Modern African Studies 41: 297-321.

Christian Aßmann is a lecturer in statistics and econometrics at the University of Bamberg (Germany). Following his study in economics, he earned a $\mathrm{PhD}$ in economics at the University of Kiel (Germany). His main areas of specialization are Bayesian estimations and nonlinear panel data models. To date he has published various articles in refereed journals including Journal of Econometrics, Computational Statistics and Data Analysis, American Journal of Human Biology, Applied Economics, International Journal of Environmental Research and Public Health, Bulletin of Economic Research and Pediatric Research. Currently he is working on a DFG-project "Analysing relations between latent competencies and context information in the National Educational Panel Study" as part of the priority programme "Education as a Lifelong Process".

Eva Krampe is an agricultural sector expert at the European Investment Bank. She studied agricultural economics and earned a PhD in agricultural economics at the University of Kiel. Her main areas of specialization are Africa's Agricultural Policy, Applied Political Economy and Economic Analysis of Agricultural Investment Projects.

Christian Henning is professor and chair of agricultural economics, University of Kiel (Germany). He studied economics, agricultural economics, sociology, political science and mathematics. He earned a PhD in economics, in agricultural economics and in political science. His main areas of specialization are applied political economy and applied economic modelling of agricultural policies. To date he has published 5 books and various articles in refereed journals including PLoS ONE, American Journal of Agricultural Economics, European Review of Agricultural Economics, Journal of Public Policy, Journal of Mathematical Sociology and Journal of Theoretical Politics.

Open Access This chapter is licensed under the terms of the Creative Commons Attribution 4.0 International License (http://creativecommons.org/licenses/by/4.0/), which permits use, sharing, adaptation, distribution and reproduction in any medium or format, as long as you give appropriate credit to the original author(s) and the source, provide a link to the Creative Commons license and indicate if changes were made.

The images or other third party material in this chapter are included in the chapter's Creative Commons license, unless indicated otherwise in a credit line to the material. If material is not included in the chapter's Creative Commons license and your intended use is not permitted by statutory regulation or exceeds the permitted use, you will need to obtain permission directly from the copyright holder.

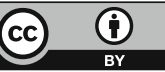

